Article

\title{
Multi-Attribute Decision Making Method Based on Aggregated Neutrosophic Set
}

\author{
Wen Jiang * $\mathbb{D}$, Zihan Zhang and Xinyang Deng \\ School of Electronics and Information, Northwestern Polytechnical University, Xi'an 710072, China; \\ zhangzihanwpu@126.com (Z.Z.); xinyang.deng@nwpu.edu.cn (X.D.) \\ * Correspondence: jiangwen@nwpu.edu.cn; Tel.: +86-29-8843-1267
}

Received: 30 December 2018; Accepted: 17 February 2019; Published: 20 February 2019

\begin{abstract}
Multi-attribute decision-making refers to the decision-making problem of selecting the optimal alternative or sorting the scheme when considering multiple attributes, which is widely used in engineering design, economy, management and military, etc. But in real application, the attribute information of many objects is often inaccurate or uncertain, so it is very important for us to find a useful and efficient method to solve the problem. Neutrosophic set is proposed from philosophical point of view to handle inaccurate information efficiently, and a single-valued neutrosophic set (SVNS) is a special case of neutrosophic set, which is widely used in actual application fields. In this paper, a new method based on single-valued neutrosophic sets aggregation to solve multi-attribute decision making problem is proposed. Firstly, the neutrosophic decision matrix is obtained by expert assessment, a score function of single-valued neutrosophic sets (SVNSs) is defined to obtain the positive ideal solution (PIS) and the negative ideal solution (NIS). Then all alternatives are aggregated based on TOPSIS method to make decision. Finally numerical examples are given to verify the feasibility and rationality of the method.
\end{abstract}

Keywords: multi-attribute decision making; single-valued neutrosophic set; aggregation; TOPSIS

\section{Introduction}

With the rapid development of human society, the social environment has become more and more complex, which makes us have difficulties in making actual decision [1-9]. Therefore, in recent years, more and more attention has been paid to multi-attribute decision making [10-16]. In the real world, the attribute information of many objects is often inaccurate or uncertain [17-23], which makes the decision progress difficult. In view of this problem, Zadeh put forward the concept of fuzzy set (FS) in 1965 [24], which made up for the lack of flexibility of classical set theory to some extent. But the traditional FS can not describe the decision information well in some conditions, Atanassov proposed the intuitionistic fuzzy set (IFS) [25] on the basis of FS. An IFS is given by $A=\left\{\left\langle x, \mu_{A}(x), v_{A}(x)\right\rangle\right\}$ where $\mu_{A}(x), v_{A}(x) \in$ $[0,1]$ denote the degree of membership and non-membership of $x$ to $A$ respectively. For instance, $A$ is an IFS in $X=\{1,2,3\}, A=(0.6,0.3) / 1+(0.7,0.1) / 2+(0.5,0.4) / 3$. Because IFSs take into account the information of membership, non-membership and hesitation simultaneously, compared with FSs, IFSs can describe the fuzzy nature [26-29] of the objective world more precisely. IFS attracted attention of many scholars, rich achievements were made in the study of intuitionistic fuzzy sets [30-33]. Torra [34] proposed another generalized form of the fuzzy set, named the hesitant fuzzy set (HFS) in 2009. HFS allowed the membership of each element in the domain to belong to a certain set which was combined by a number of different values. The element of the HFS is named as the hesitant fuzzy element (HFE) by Xia et al. [35], the mathematical symbol of HFS is expressed by Xia as $A=\left\{\left\langle x, h_{A}(x)\right\rangle \mid x \in X\right\}$ where $h_{A}(x)$ is set of some values in $[0,1]$, denoting the possible membership degrees of element $x \in X$ to the set $A$. $h_{A}(x)$ is called a HFE. For example, $B$ is a HFS in $X=\{1,2,3\}$ 
and $B=\{0.6,07,0.8\} / 1+\{0.2\} / 2+\{0.3,0.9\} / 3$. The addition and multiplication operations on the hesitant fuzzy element are also given by Xia. The hesitant intuitionistic fuzzy sets (HIFSs) is proposed by Zhou et al. [36]. Zhou proposed that the HIFSs here were the generalization of the IFSs. The group decision-making method under the condition of the uncertain intuitionistic fuzzy priority relation matrix and aggregation operator was also given by Zhou in that paper.

The IFS considers both the truth-membership $T_{A}(x)$ and the falsity membership $F_{A}(x)$ with $T_{A}(x), F_{A}(x) \in[0,1]$ and $0 \leq T_{A}(x)+F_{A}(x) \leq 1$. For IFSs, the indeterminacy is $1-T_{A}(x)-F_{A}(x)$ by default. The IFS can handle incomplete information but can hardly process inaccurate information.

In order to better describe uncertain information, Smarandache introduced Neutrosophy in 1995 [37,38]. Neutrosophy is a kind of philosophy which studies the nature, scope, and origin of neutralities, as well as their joint parts with different ideational spectra [37]. Neutrosophic set (NS) was also propose by Smarandache. NS is a very powerful tool which generalizes the concept of the classic set, fuzzy set, interval-valued fuzzy set, IFS, interval-valued intuitionistic fuzzy set [39], dialetheist set, paraconsistent set, and tautological set [37]. A NS $A$ is defined on a universe of discourse $u$. An element $x$ in set $A$ is expressed as $x=x(t, i, f) \in A$, where $t$ is a truth-membership function, $i$ is an indeterminacy-membership function, and $f$ is a falsity-membership function, $t, i$, and $f$ are the real standard or non-standard subsets of $] 0^{-}, 1^{+}[$. For a NS, the indeterminacy is denoted explicitly in contrast of that of IFSs. The indeterminacy can be divided into more parts so as to better express the inaccurate information [37]. However neutrosophic sets are hard to use in actual occasions. So Wang et al. [40] proposed the concept of single-valued neutrosophic sets (SVNSs). For instance, $C=(0.7,0.5,0.2)$ is a SVNS, in which the truth-membership $t=0.7$, the indeterminacy $i=0.5$ and the falsity-membership $f=0.2$. Because SVNS are easy to express the inaccurate information, SVNSs are widely used in actual situations, such as in medicine [41], image processing [42], multi-criteria decision-making [43-47], fault diagnosis [41,48,49], etc.

Neutrosophic set has many advantages in handling uncertain information. A lot of researches are conducted on it. In [50], SVNS is used to express the decision information, weighted average operator, TOPSIS method is adopted to propose the multi-criteria decision making method. Peng introduced relevant concepts about the interval neutrosophic set [51], and the multi-criteria decision making problem is also analyzed by combining the ranking method. Jiang proposed a new method to measure the similarity between SVNSs using Dempster-Shafer evidence theory [52]. Ye proposed a method to make decision based on the weighted correlation coefficient of SVNSs in [44], and proposed another method to make decision in multi-criteria environment based on single valued neutrosophic cross-entropy in [45]. Ye utilized cross entropy between the ideal solution and an alternative to get the rank of all alternatives according to the values of cross entropy and to choose the most suitable one(s). A decision method for the interval neutrosophic set is proposed based on cross entropy by Tian et al. [53]. Deli applied bipolar neutrosophic sets to multi-criteria decision situations [54]. The TOPSIS method can be effectively combined with SVNSs to accomplish multi-attribute decision making problems. By the way, the key point of TOPSIS is that the ideal alternative should have the shortest distance from the PIS and the farthest distance from the NIS. The standard TOPSIS to new multi-attribute decision-making called simplified-TOPSIS is proposed by Elhassouny [55], which simplifies the process of the classical TOPSIS and get the same result.

This paper mainly introduces a new multi-attribute decision-making method based on SVNSs. First, based on the given decision matrix, use score function to get the PIS and the NIS. Second, aggregate all alternatives to get aggregated neutrosophic set. Last, use TOPSIS method to rank all alternatives to make decision.

The paper is organized as follow. In Section 2, we present some preliminaries. Section 3 will focus on the proposed multi-criteria decision method based on aggregated neutrosophic set. Afterwards, two illustrative examples are introduced in Section 4. In the final section, conclusions are drawn. 


\section{Preliminaries}

A brief review of some preliminaries will be given in the following part.

\subsection{Neutrosophic Sets}

Neutrosophic set is an efficient tool to deal with the uncertain information. In [37], Smarandache gave the definitions about a NS as follow:

Definition 1. $Y$ is a universal space of point (objects) with a generic element of $Y$ denoted by $y$. A neutrosophic set $N \subset Y$ is consist of a truth-membership function $T_{N}(y)$, an indeterminacy-membership function $I_{N}(y)$ and a falsity-membership function $F_{N}(y) . T_{A}(y)$, These three components are real standard or real nonstandard subset of $\left[0^{-}, 1^{+}\right]$. So that all three components

$$
\begin{aligned}
& T_{N}(y) \rightarrow\left[0^{-}, 1^{+}\right] \\
& I_{N}(y) \rightarrow\left[0^{-}, 1^{+}\right] \\
& F_{N}(y) \rightarrow\left[0^{-}, 1^{+}\right]
\end{aligned}
$$

$T_{N}(y), I_{N}(y)$ and $F_{N}(y)$ are related as follow:

$$
0^{-} \leq \sup T_{N}(y)+\sup I_{N}(y)+\sup F_{N}(y) \leq 3^{+} .
$$

Definition 2. A neutrosophic set $N$ has its' complement which is characterized by $N^{c}$ and is characterized as

$$
\begin{aligned}
& T_{N}^{c}(y)=1^{+}-T_{N}(y) \\
& I_{N}^{c}(y)=1^{+}-I_{N}(y) \\
& F_{N}^{c}(y)=1^{+}-F_{N}(y)
\end{aligned}
$$

for every y in $Y$.

\subsection{SVNS}

For NS is difficult to be used in practical occasions, Wang [40] proposed the concept of single-valued neutrosophic sets (SVNSs), which can be easily used in actual situations. The definition of SVNSs are introduced as follow:

Definition 3. Let $Y$ be a space of points (objects) which generic elements in $Y$ denoted by y. A SVNS $N$ is characterized by a truth-membership function $T_{N}$, an indeterminacy-membership function $I_{N}$, and a falsity-membership function $F_{N}$ with $T_{N}, I_{N}, F_{N} \in[0,1]$.

When $Y$ is continuous, an SVNS N can be expressed as:

$$
N=\int_{X}\left\langle T_{N}(y), I_{N}(y), F_{N}(y)\right\rangle \mid y, \quad y \in Y .
$$

When $Y$ is discrete, an SVNS N can be characterized as:

$$
N=\sum_{y}\left\langle T_{N}(y), I_{N}(y), F_{N}(y)\right\rangle \mid y, \quad y \in Y
$$

For convenience, a SVNS is usually denoted by its' simplified symbol $N=\left\langle T_{N}(Y), I_{N}(Y), F_{N}(Y)\right\rangle$ for all $y \in Y$. 
Definition 4. A SVNS N has its' complement $N^{c}$ which is characterized as

$$
\begin{gathered}
T_{N}^{c}(y)=F_{N}(y) \\
I_{N}^{c}(y)=1-I_{N}(y) \\
F_{N}^{c}(y)=T_{N}(y)
\end{gathered}
$$

for all $y$ in $Y$.

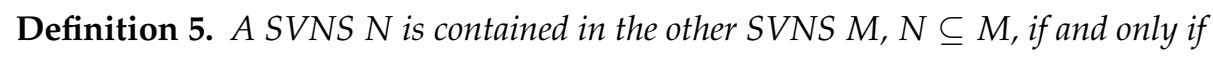

$$
\begin{aligned}
& T_{N}(y) \leq T_{M}(y) \\
& I_{N}(y) \geq I_{M}(y) \\
& F_{N}(y) \geq F_{M}(y)
\end{aligned}
$$

for all $y$ in $Y$.

Definition 6. Two SVNSs $N$ and $M$ are equal, written as $N=M$, if and only if $N \subseteq M$ and $N \subseteq M$.

\subsection{Score Function}

Definition 7. Assume $A=\left(T_{A}, I_{A}, F_{A}\right)$ be a single valued neutrosophic number, then the score function [56] is defined as

$$
S(A)=\frac{T_{A}-I_{A}-F_{A}}{3} .
$$

Score function is a very useful tool to illustrate which neutrosophic number is better. For example, $A_{1}=(0.5,0.3,0.4), A_{2}=(0.6,0.4,0.5)$, use the score function and get $S\left(A_{1}\right)=-\frac{2}{15}, S\left(A_{2}\right)=-\frac{1}{6}$, $S\left(A_{1}\right)>S\left(A_{2}\right)$, this result is in line with intuition, in this case, $A_{1}$ is better than $A_{2}$.

\subsection{Distance between Two Neutrosophic Sets}

Assume that there two NSs, shows as follow:

$$
\begin{gathered}
M=\left\langle t_{M}\left(x_{i}\right), i_{M}\left(x_{i}\right), f_{M}\left(x_{i}\right)\right\rangle \quad i=1,2, \ldots, n \\
N=\left\langle t_{N}\left(x_{i}\right), i_{N}\left(x_{i}\right), f_{N}\left(x_{i}\right)\right\rangle \quad i=1,2, \ldots, n
\end{gathered}
$$

Then the Hamming distance between $M$ and $N$ is defined as follow:

$$
d_{1}(M, N)=\sum_{i=1}^{n}\left\{\left|t_{M}\left(x_{i}\right)-t_{N}\left(x_{i}\right)\right|+\left|i_{M}\left(x_{i}\right)-i_{N}\left(x_{i}\right)\right|+\left|f_{M}\left(x_{i}\right)-f_{N}\left(x_{i}\right)\right|\right\}
$$

the standard Hamming distance between $M$ and $N$ is defined as follow:

$$
d_{2}(M, N)=\frac{1}{3 n} \sum_{i=1}^{n}\left\{\left|t_{M}\left(x_{i}\right)-t_{N}\left(x_{i}\right)\right|+\left|i_{M}\left(x_{i}\right)-i_{N}\left(x_{i}\right)\right|+\left|f_{M}\left(x_{i}\right)-f_{N}\left(x_{i}\right)\right|\right\}
$$

the Euclid distance between $M$ and $N$ is defined as follow:

$$
d_{3}(M, N)=\sqrt{\sum_{i=1}^{n}\left\{\left(t_{M}\left(x_{i}\right)-t_{N}\left(x_{i}\right)\right)^{2}+\left(i_{M}\left(x_{i}\right)-i_{N}\left(x_{i}\right)\right)^{2}+\left(f_{M}\left(x_{i}\right)-f_{N}\left(x_{i}\right)\right)^{2}\right\}}
$$


the standard Euclid distance between $M$ and $N$ is defined as follow:

$$
d_{4}(M, N)=\sqrt{\frac{1}{3 n} \sum_{i=1}^{n}\left\{\left(t_{M}\left(x_{i}\right)-t_{N}\left(x_{i}\right)\right)^{2}+\left(i_{M}\left(x_{i}\right)-i_{N}\left(x_{i}\right)\right)^{2}+\left(f_{M}\left(x_{i}\right)-f_{N}\left(x_{i}\right)\right)^{2}\right\}}
$$

\section{An Improved Multi-Criteria Decision Making Method}

Multi-criteria decision making often faces complex environments. At present, multi-criteria decision making methods mostly handle multiple attributes of an alternative separately for decision making. Few studies try to aggregate all neutrosophic sets of one alternative before decision making to simplify the decision progress. Based on the idea of information fusion, the NSs can be aggregated before using TOPSIS method to make a decision. In this way, decision progress can be simplified. A multi-attribute decision making method based on aggregated SVNSs is introduced in this part.

step1: Construct neutrosophic decision matrix.

The single-valued neutrosophic decision matrix is constructed based on expert assessments. For instance, when an expert is asked the opinion of an alternative $A_{1}$ with respect to a criterion $C_{1}$, the expert may say that possibility in which the alternative is good is 0.5 and false degree is 0.4 and the expert is not sure is 0.2 . For the NS, it can be expressed as $d_{11}=\langle 0.5,0.2,0.4\rangle$.

Assume there are $m$ alternatives and $n$ criteria. The neutrosophic decision matrix $D$ is expressed as follow:

$$
\left[\begin{array}{cccc}
d_{11} & d_{12} & \ldots & d_{1 n} \\
d_{21} & d_{22} & \ldots & d_{2 n} \\
\vdots & \vdots & \ddots & \vdots \\
d_{m 1} & d_{m 2} & \ldots & d_{m n}
\end{array}\right]
$$

where $d_{i j}=\left(T_{i j}, I_{i j}, F_{i j}\right), 1 \leq i \leq m, 1 \leq j \leq n, T_{i j}, I_{i j}, F_{i j}$ are the truth-membership degree, the indeterminacy-membership degree, the falsity-membership degree of alternative $A_{i}$ with respect to criterion $j$.

step2: Determine the PIS and the NIS.

In this step, score function mentioned above is utilized to get the PIS $A^{*}$ and the NIS $A^{-*}$.

Assume $A^{*}=\left(d_{1}^{*}, d_{2}^{*}, \ldots, d_{n}^{*}\right)$, among them $S\left(d_{j}^{*}\right)=\max _{i}\left\{S\left(d_{i j}\right)\right\}, j=1,2, \ldots, n$, and $A^{-*}=$ $\left(d_{1}^{-*}, d_{2}^{-*}, \ldots, d_{n}^{-*}\right)$ among them $S\left(d_{j}^{-*}\right)=\min _{i}\left\{S\left(d_{i j}\right)\right\}, j=1,2, \ldots, n$, the score function can be used to illustrate that how good or bad a neutrosophic set is. A simple example is given as follow:

Example 1. Assume there is a decision matrix which is obtained from expert assessments showing as follow:

$$
\left[\begin{array}{ccc}
(0.4,0.2,0.3) & (0.4,0.2,0.4) & (0.5,0.2,0.2) \\
(0.6,0.1,0.2) & (0.6,0.1,0.2) & (0.2,0.2,0.5) \\
(0.7,0.1,0.1) & (0.5,0.3,0.3) & (0.4,0.3,0.2)
\end{array}\right]
$$

Specifically, let us consider the neutrosophic set $(0.4,0.2,0.3), T_{11}=0.4, I_{11}=0.2, F_{11}=0.3$, use Equation (3) to obtain the score function as follows:

$$
S\left(d_{11}\right)=\frac{0.4-0.2-0.3}{3}=-\frac{1}{30}
$$

In this way, scores of all neutrosophic sets can be obtained, neutrosophic sets which have the highest or the lowest scores will be choose to constitute the PIS $\left(A^{*}\right)$ and the NIS $\left(A^{-*}\right)$. For example, in the first column of the matrix:

$$
S\left(d_{11}\right)=-\frac{1}{30}, S\left(d_{21}\right)=\frac{1}{10}, S\left(d_{31}\right)=\frac{1}{6}
$$


In this case, $d_{31}$ and $d_{11}$ are chosen to constitute the first column of $A^{*}$ and $A^{-*}$ respectively. $A^{*}$ and $A^{-*}$ can be obtained as follow:

$$
\begin{aligned}
& A^{*}=((0.7,0.1,0.1),(0.6,0.1,0.2),(0.5,0.2,0.2)) \\
& A^{-*}=((0.4,0.2,0.3),(0.4,0.2,0.4),(0.2,0.2,0.5))
\end{aligned}
$$

step3: Aggregate the SVNSs.

In this step, all the attributes of a neutrosophic set are aggregated. Arithmetic average method is used to combine neutrosophic set. $A_{j}^{a}=\left(t_{j}^{a}, i_{j}^{a}, f_{j}^{a}\right)$ is the aggregated neutrosophic set, $1 \leq j \leq m$, where

$$
\begin{aligned}
t_{j}^{a} & =\frac{t_{j 1}+t_{j 2}+\ldots+t_{j n}}{n} \\
i_{j}^{a} & =\frac{i_{j 1}+i_{j 2}+\ldots+i_{j n}}{n} \\
f_{j}^{a} & =\frac{f_{j 1}+f_{j 2}+\ldots+f_{j n}}{n}
\end{aligned}
$$

$n$ is the number of attributes.

This method is used to aggregate all the alternatives, the PIS and the NIS. So $A_{j}^{a}=\left(t_{j}^{a}, i_{j}^{a}, f_{j}^{a}\right), 1 \leq$ $j \leq m, A^{* a}=\left(t^{* a}, i^{* a}, f^{* a}\right)$ and $A^{-* a}=\left(t^{-* a}, i^{-* a}, f^{-* a}\right)$ are obtained.

step4: Multi-criteria decision making based on TOPSIS method

In this step, TOPSIS method is utilized to finish a multi-attribute neutrosophic decision making. In step 3, the aggregated SVNSs, the aggregated PIS and NIS are obtained. Then the distance for each aggregated SVNS between $A^{* a}$ and between $A^{-* a}$ can be calculated by Euclid distance Equation (8). The distance between $A_{j}^{a}$ and $A^{* a}$ is calculated as follows:

$$
D_{j}^{*}=\sqrt{\left(t_{j}^{a}-t^{* a}\right)^{2}+\left(i_{j}^{a}-i^{* a}\right)^{2}+\left(f_{j}^{a}-f^{* a}\right)^{2}} \quad j=1,2, \ldots, m
$$

The distance between $A_{j}^{a}$ and $A^{-* a}$ is got as follows:

$$
D_{j}^{-*}=\sqrt{\left(t_{j}^{a}-t^{-* a}\right)^{2}+\left(i_{j}^{a}-i^{-* a}\right)^{2}+\left(f_{j}^{a}-f^{-* a}\right)^{2}} \quad j=1,2, \ldots, m
$$

The relative closeness $T_{j}$ based on TOPSIS is got as follows:

$$
T_{j}=\frac{D_{j}^{-*}}{\left(D_{j}^{-*}+D_{j}^{*}\right)} \quad j=1,2, \ldots, m
$$

Obviously, the bigger the value of $T_{j}$ is, the farther the alternative is from the NIS, and the closer the alternative is to the PIS, and vice versa. The ranked of all the alternatives is obtained in the descending order of the value of $T_{j}$.

\section{Illustrative Example}

In this section, two examples are used to demonstrate the application of the proposed method.

Example 2. Let us consider the decision-making problem originated from [56]. There is an investment company which wants to invest some money in a schools. There are four possible schools to invest the money: $\left\{A_{1}, A_{2}, A_{3}, A_{4}\right\}$. The investment company is going to choose one school to invest with respect to the following four criteria: $\left\{C_{1}, C_{2}, C_{3}, C_{4}\right\}$.

Step1: Experts evaluate all the four possible schools according to the four attributes. According to the evaluation results, the following SVNS decision matrix is shown in Table 1: 
Table 1. Solution matrix for SVNS.

\begin{tabular}{ccccc}
\hline & $\boldsymbol{C}_{\mathbf{1}}$ & $\boldsymbol{C}_{\mathbf{2}}$ & $\boldsymbol{C}_{\mathbf{3}}$ & $\boldsymbol{C}_{\mathbf{4}}$ \\
\hline$A_{1}$ & $(0.6,0.3,0.5)$ & $(0.5,0.7,0.6)$ & $(0.7,0.6,0.5)$ & $(0.5,0.5,0.6)$ \\
$A_{2}$ & $(0.6,0.4,0.5)$ & $(0.4,0.5,0.6)$ & $(0.3,0.5,0.6)$ & $(0.4,0.5,0.6)$ \\
$A_{3}$ & $(0.5,0.6,0.7)$ & $(0.7,0.2,0.8)$ & $(0.7,0.6,0.3)$ & $(0.4,0.4,0.5)$ \\
$A_{4}$ & $(0.4,0.3,0.2)$ & $(0.5,0.4,0.3)$ & $(0.6,0.7,0.2)$ & $(0.4,0.3,0.2)$ \\
\hline
\end{tabular}

Step2: Then the score function is utilized to get $A^{*}$ and $A^{-*}$. The calculation results are expressed in Table 2:

Table 2. Scores matrix for SVNS.

\begin{tabular}{lrrrr}
\hline & $C_{1}$ & $C_{2}$ & $C_{3}$ & $C_{4}$ \\
\hline$A_{1}$ & $-\frac{1}{15}$ & $-\frac{4}{15}$ & $-\frac{2}{15}$ & $-\frac{1}{5}$ \\
$A_{2}$ & $-\frac{1}{10}$ & $-\frac{7}{30}$ & $-\frac{4}{15}$ & $-\frac{7}{30}$ \\
$A_{3}$ & $-\frac{4}{15}$ & $-\frac{1}{10}$ & $-\frac{1}{15}$ & $-\frac{1}{6}$ \\
$A_{4}$ & $-\frac{1}{30}$ & $-\frac{1}{15}$ & $-\frac{1}{10}$ & $-\frac{1}{30}$ \\
\hline
\end{tabular}

From Table 2, $S\left(d_{41}\right)=-\frac{1}{30}$ is the maximum in the first column, $S\left(d_{42}\right), S\left(d_{33}\right), S\left(d_{44}\right)$ is the maximum in column 2,3,4 respectively. The neutrosophic PIS $A^{*}$ is composed of $d_{41}, d_{42}, d_{33}, d_{44}$. Similarly, the $d_{i j}$ which has the minimum score in each column is chosen to constitute the neutrosophic NIS $A^{-*}$. The PIS $A^{*}$ and the NIS $A^{-*}$ can be obtained as follow:

$$
\begin{gathered}
A^{*}=((0.4,0.3,0.2),(0.5,0.4,0.3),(0.7,0.6,0.3),(0.4,0.3,0.2)) \\
A^{-*}=((0.5,0.6,0.7),(0.5,0.7,0.6),(0.3,0.5,0.6),(0.4,0.5,0.6))
\end{gathered}
$$

Step3: Aggregate all the alternatives, $A^{*}$ and $A^{-*}$. For example:

$$
A^{*}=((0.4,0.3,0.2),(0.5,0.4,0.3),(0.7,0.6,0.3),(0.4,0.3,0.2))
$$

The $T_{A^{*}}, I_{A^{*}}, F_{A^{*}}$ of $A_{c}^{*}$ can be obtained as follow:

$$
\begin{gathered}
T_{A^{*}}=\frac{0.4+0.5+0.7+0.4}{4}=0.500 \\
I_{A^{*}}=\frac{0.3+0.4+0.6+0.3}{4}=0.400 \\
F_{A^{*}}=\frac{0.2+0.3+0.3+0.2}{4}=0.250 \\
A_{c}^{*}=\left(T_{A^{*}}, I_{A^{*}}, F_{A^{*}}\right)=(0.500,0.400,0.250)
\end{gathered}
$$

All aggregated neutrosophic sets are obtained in the same way and shown as follow:

$$
\begin{aligned}
& A_{1 c}=(0.575,0.525,0.550) \\
& A_{2 c}=(0.425,0.475,0.575) \\
& A_{3 c}=(0.575,0.450,0.575) \\
& A_{4 c}=(0.475,0.425,0.225) \\
& A_{c}^{*}=(0.500,0.400,0.250) \\
& A_{c}^{-*}=(0.425,0.575,0.625)
\end{aligned}
$$


Step4: All alternatives are ranked by the TOPSIS method. Euclid distances between alternatives and the PIS are calculated as follow:

$$
\begin{aligned}
& d\left(A_{1 c}, A_{c}^{*}\right)=\sqrt{\left(T_{A_{1 c}}-T_{A_{c}^{*}}\right)^{2}+\left(I_{A_{1 c}}-I_{A_{c}^{*}}\right)^{2}+\left(F_{A_{1 c}}-F_{A_{c}^{*}}\right)^{2}}=0.334 \\
& d\left(A_{2 c}, A_{c}^{*}\right)=\sqrt{\left(T_{A_{2 c}}-T_{A_{c}^{*}}\right)^{2}+\left(I_{A_{2 c}}-I_{A_{c}^{*}}\right)^{2}+\left(F_{A_{2 c}}-F_{A_{c}^{*}}\right)^{2}}=0.342 \\
& d\left(A_{3 c}, A_{c}^{*}\right)=\sqrt{\left(T_{A_{3 c}}-T_{A_{c}^{*}}\right)^{2}+\left(I_{A_{3 c}}-I_{A_{c}^{*}}\right)^{2}+\left(F_{A_{3 c}}-F_{A_{c}^{*}}\right)^{2}}=0.337 \\
& d\left(A_{4 c}, A_{c}^{*}\right)=\sqrt{\left(T_{A_{4 c}}-T_{A_{c}^{*}}\right)^{2}+\left(I_{A_{4 c}}-I_{A_{c}^{*}}\right)^{2}+\left(F_{A_{4 c}}-F_{A_{c}^{*}}\right)^{2}}=0.043
\end{aligned}
$$

Euclid distances between alternatives and the NIS are calculated as follow:

$$
\begin{aligned}
& d\left(A_{1 c}, A_{c}^{-*}\right)=\sqrt{\left(T_{A_{1 c}}-T_{A_{c}^{-*}}\right)^{2}+\left(I_{A_{1 c}}-I_{A_{c}^{-*}}\right)^{2}+\left(F_{A_{1 c}}-F_{A_{c}^{-*}}\right)^{2}}=0.175 \\
& d\left(A_{2 c}, A_{c}^{-*}\right)=\sqrt{\left(T_{A_{2 c}}-T_{A_{c}^{-*}}\right)^{2}+\left(I_{A_{2 c}}-I_{A_{c}^{-*}}\right)^{2}+\left(F_{A_{2 c}}-F_{A_{c}^{-*}}\right)^{2}}=0.112 \\
& d\left(A_{3 c}, A_{c}^{-*}\right)=\sqrt{\left(T_{A_{3 c}}-T_{A_{c}^{-*}}\right)^{2}+\left(I_{A_{3 c}}-I_{A_{c}^{-*}}\right)^{2}+\left(F_{A_{3 c}}-F_{A_{c}^{-*}}\right)^{2}}=0.202 \\
& d\left(A_{4 c}, A_{c}^{-*}\right)=\sqrt{\left(T_{A_{4 c}}-T_{A_{c}^{-*}}\right)^{2}+\left(I_{A_{4 c}}-I_{A_{c}^{-*}}\right)^{2}+\left(F_{A_{4 c}}-F_{A_{c}^{-*}}\right)^{2}}=0.430
\end{aligned}
$$

The relative closeness are calculated as follow:

$$
\begin{aligned}
& T_{1}=\frac{d\left(A_{1 c}, A_{c}^{-*}\right)}{d\left(A_{1 c}, A_{c}^{-*}\right)+d\left(A_{1 c}, A_{c}^{*}\right)}=0.344 \\
& T_{2}=\frac{d\left(A_{2 c}, A_{c}^{-*}\right)}{d\left(A_{2 c}, A_{c}^{-*}\right)+d\left(A_{2 c}, A_{c}^{*}\right)}=0.247 \\
& T_{3}=\frac{d\left(A_{3 c}, A_{c}^{-*}\right)}{d\left(A_{3 c}, A_{c}^{-*}\right)+d\left(A_{3 c}, A_{c}^{*}\right)}=0.375 \\
& T_{4}=\frac{d\left(A_{4 c}, A_{c}^{-*}\right)}{d\left(A_{4 c}, A_{c}^{-*}\right)+d\left(A_{4 c}, A_{c}^{*}\right)}=0.909
\end{aligned}
$$

Rank the $T_{i}, i=1,2,3,4$ in descending order, and get $T_{4}>T_{3}>T_{1}>T_{2}$. In this case, $A_{4}$ is chosen as the ideal solution. This example shows that by using the proposed method decision results can be easily obtained.

Example 3. For a further understanding and comparison of our approach, another problem is considered. The data in this example originated from [57]. Let us suppose that decision makers intend to select the most suitable tablet from the four chosen tablets $\left(A_{1}, A_{2}, A_{3}, A_{4}\right)$ by considering six attributes namely: Features $C_{1}$, Hardware $C_{2}$, Display $C_{3}$, Communication $C_{4}$, Affordable Price $C_{5}$, Customer care $C_{6}$. By using the presented method, the problem is handled by the following steps.

Step1: Assume that $A_{i}\left(A_{1}, A_{2}, A_{3}, A_{4}\right)$ are alternatives with respect to six criteria $\left(C_{1}, C_{2}, C_{3}, C_{4}, C_{5}, C_{6}\right)$. Neutrosophic decision matrix are shown in Table 3: 
Table 3. Neutrosophic decision matrix.

\begin{tabular}{cccc}
\hline & $C_{1}$ & $C_{2}$ & $C_{3}$ \\
$A_{1}$ & $(0.864,0.136,0.081)$ & $(0.853,0.147,0.092)$ & $(0.800,0.200,0.150)$ \\
$A_{2}$ & $(0.667,0.333,0.277)$ & $(0.727,0.273,0.219)$ & $(0.667,0.333,0.277)$ \\
$A_{3}$ & $(0.880,0.120,0.067)$ & $(0.887,0.113,0.064)$ & $(0.834,0.166,0.112)$ \\
$A_{4}$ & $(0.667,0.333,0.277)$ & $(0.735,0.265,0.195)$ & $(0.768,0.232,0.180)$ \\
& $C_{4}$ & $C_{5}$ & $C_{6}$ \\
$A_{1}$ & $(0.704,0.296,0.241)$ & $(0.823,0.177,0.123)$ & $(0.864,0.136,0.081)$ \\
$A_{2}$ & $(0.744,0.256,0.204)$ & $(0.652,0.348,0.293)$ & $(0.608,0.392,0.336)$ \\
$A_{3}$ & $(0.779,0.256,0.204)$ & $(0.811,0.189,0.109)$ & $(0.850,0.150,0.092)$ \\
$A_{4}$ & $(0.727,0.273,0.221)$ & $(0.791,0.209,0.148)$ & $(0.808,0.192,0.127)$ \\
\hline
\end{tabular}

Step2: Score function are used to calculate and get the score matrix in Table 4.

Table 4. Score matrix.

\begin{tabular}{ccccccc}
\hline & $C_{1}$ & $C_{\mathbf{2}}$ & $C_{\mathbf{3}}$ & $\boldsymbol{C}_{\mathbf{4}}$ & $\boldsymbol{C}_{\mathbf{5}}$ & $\boldsymbol{C}_{\mathbf{6}}$ \\
\hline$A_{1}$ & 0.216 & 0.205 & 0.150 & 0.056 & 0.174 & 0.216 \\
$A_{2}$ & 0.019 & 0.078 & 0.019 & 0.095 & 0.004 & -0.040 \\
$A_{3}$ & 0.231 & 0.237 & 0.185 & 0.106 & 0.171 & 0.203 \\
$A_{4}$ & 0.019 & 0.092 & 0.119 & 0.078 & 0.145 & 0.163 \\
\hline
\end{tabular}

From Table 4, the neutrosophic PIS can be got as follow:

$$
\begin{gathered}
A^{*}=((0.880,0.120,0.067),(0.887,0.113,0.064),(0.834,0.166,0.112), \\
(0.779,0.256,0.204),(0.823,0.177,0.123),(0.864,0.136,0.081))
\end{gathered}
$$

and the neutrosophic NIS is shown as follow:

$$
\begin{gathered}
A^{-*}=((0.667,0.333,0.277),(0.727,0.273,0.219),(0.667,0.333,0.277), \\
(0.704,0.296,0.241),(0.652,0.348,0.293),(0.608,0.392,0.336)) .
\end{gathered}
$$

Step3: Neutrosophic sets aggregation is done in this step. After calculation, results are shown as follows:

$$
\begin{aligned}
& A_{1 c}=(0.818,0.182,0.128) \\
& A_{2 c}=(0.677,0.323,0.268) \\
& A_{3 c}=(0.840,0.166,0.108) \\
& A_{4 c}=(0.749,0.251,0.191) \\
& A_{c}^{*}=(0.844,0.161,0.109) \\
& A_{c}^{-*}=(0.671,0.329,0.274)
\end{aligned}
$$

Step4: In the last step, Euclid distances between $A_{i c}, i=1,2,3,4$ and $A_{c}^{*}$ and between $A_{i c}, i=1,2,3,4$ and $A_{c}^{-*}$ are obtained, and the relative closeness of each alternative $T_{i}(i=1,2,3,4)$ is obtained. Euclid distances between alternatives and the neutrosophic PIS are as follow:

$$
\begin{aligned}
& d\left(A_{1 c}, A_{c}^{*}\right)=0.038 \quad d\left(A_{2 c}, A_{c}^{*}\right)=0.282 \\
& d\left(A_{3 c}, A_{c}^{*}\right)=0.007 \quad d\left(A_{4 c}, A_{c}^{*}\right)=0.154
\end{aligned}
$$


Euclid distances between alternatives and the neutrosophic NIS are below:

$$
\begin{aligned}
& d\left(A_{1 c}, A^{-*}\right)=0.254 \quad d\left(A_{2 c}, A^{-*}\right)=0.011 \\
& d\left(A_{3 c}, A^{-*}\right)=0.288 \quad d\left(A_{4 c}, A^{-*}\right)=0.138
\end{aligned}
$$

So the relative closeness of each alternative to the ideal solution can be easily obtained as follow:

$$
\begin{array}{ll}
T_{1}=0.870 & T_{2}=0.038 \\
T_{3}=0.976 & T_{4}=0.473
\end{array}
$$

the rank of them can be obtained: $T_{3}>T_{1}>T_{4}>T_{2}$. Obviously, $A_{3}$ is the best solution.

According to the results, method which uses aggregated SVNSs in this paper is more simplified than that proposed by Pramanik [57]. Additionally, the Pramanik's results are shown as follow:

$$
\begin{array}{ll}
T_{1}=0.8190 & T_{2}=0,1158 \\
T_{3}=0.8605 & T_{4}=0.4801
\end{array}
$$

The same rank of alternatives are got, but in our approach the difference between the data is greater and the results are clearer than that in Pramanik's. The presented method is different with Pramanik's method in handling the attributes. In Pramanik's method, attribute weight is used to revise the neutrosophic set. In the presented method neutrosophic sets of different attributes are aggregated to one neutrosophic set, which simplifies the decision-making process and makes the process more efficient. In this way, multi-criteria decision making can be easily made.

To verify the rationality and usefulness of the presented method, correlation coefficient method [44] and cross-entropy method [45] are used to calculate the same decision problem in Table 3. In Table 3, $B_{i}$ refers to the correlation between alternative $A_{i}$ and the PIS $A^{*}$, and $E_{i}$ refers to the distance between $A_{i}$ and the PIS $A^{*}$. The comparison of presented method with these three methods are shown in Table 5.

Table 5. Comparison with other methods.

\begin{tabular}{cccc}
\hline Methods & Indexes for Decision Making & Rank of Indexes & The Chosen Alternative \\
\hline Elhassouny's [57] & $T_{1}=0.8190, T_{2}=0,1158, T_{3}=0.8605, T_{4}=0.4801$ & $T_{3}>T_{1}>T_{4}>T_{2}$ & $A_{3}$ \\
correlation coefficient [44] & $B_{1}=0.959, B_{2}=0.846, B_{3}=0.970, B_{4}=0.917$ & $B_{3}>B_{1}>B_{4}>B_{2}$ & $A_{3}$ \\
cross-entropy [45] & $E_{1}=0.530, E_{2}=0.966, E_{3}=0.466, E_{4}=0.763$ & $E_{3}<E_{1}<E_{4}<E_{2}$ & $A_{3}$ \\
Presented method & $T_{1}=0.870, T_{2}=0.038, T_{3}=0.976, T_{4}=0.473$ & $T_{3}>T_{1}>T_{4}>T_{2}$ & $A_{3}$ \\
\hline
\end{tabular}

\section{Conclusions}

In this paper, a multi-attribute decision method used aggregated neutrosophic set and TOPSIS is proposed. In our method, arithmetic average method is used to aggregate neutrosophic sets, and aggregated sets can be used by TOPSIS method to get a final rank. The proposed approach could reduce the computation since it firstly aggregate the neutrosophic sets before ranking, so it is useful in real application with high requirements of real-time. Two examples have demonstrated the rationality and feasibility of our approach. However, this method also has some limitations, averaging the validity of the criteria may lead to the loss of some criteria information. If the criteria information is especially emphasized in the decision process, this presented method may be not so appropriate to be used. In the future, more work will be done on the score function to make the decision making process more accurate, and the geometric average method is also need to be checked. Continuous work in the application of complex decision-making problems such as group decision-making problems and other domains such as fuzzy system is also need to be done.

Author Contributions: W.J. and X.D. proposed the method; W.J., Z.Z. and X.D. analyzed the results of experiment; Z.Z. wrote the paper; W.J. and X.D. revised and improved the paper. 
Funding: The work is partially supported by National Natural Science Foundation of China (Program No. 61671384, 61703338), Natural Science Basic Research Plan in Shaanxi Province of China (Program No. 2018JQ6085).

Conflicts of Interest: The authors declare that there is no conflict of interest regarding the publication of this paper.

\section{References}

1. Jiang, W. A correlation coefficient for belief functions. Int. J. Approx. Reason. 2018, 103, 94-106. [CrossRef]

2. Deng, X.; Jiang, W.; Wang, Z. Zero-sum polymatrix games with link uncertainty: A Dempster-Shafer theory solution. Appl. Math. Comput. 2019, 340, 101-112. [CrossRef]

3. Kahneman, D.; Tversky, A. Prospect Theory. An analysis of decision making under risk. Econometrica 1979, 47, 263-291. [CrossRef]

4. Han, Y.; Deng, Y. A hybrid intelligent model for Assessment of critical success factors in high risk emergency system. J. Ambient Intell. Humaniz. Comput. 2018, 9, 1933-1953. [CrossRef]

5. Bellman, R.E.; Zadeh, L.A. Decision-Making in a Fuzzy Environment. Manag. Sci. 1970, 17, B141-B164. [CrossRef]

6. Wendt, D.; Vlek, C. Utility, Probability, and Human Decision Making. Soc. Sci. Electron. Publ. 1977, 185, 1124-1131.

7. Xiao, F. Multi-sensor data fusion based on the belief divergence measure of evidences and the belief entropy. Inf. Fusion 2019, 46, 23-32. [CrossRef]

8. Zhang, L.; Wu, X.; Zhu, H.; AbouRizk, S.M. Perceiving safety risk of buildings adjacent to tunneling excavation: An information fusion approach. Autom. Constr. 2017, 73, 88-101. [CrossRef]

9. He, Z.; Jiang, W. An evidential Markov decision making model. Inf. Sci. 2018, 467, 357-372. [CrossRef]

10. He, Z.; Jiang, W. An evidential dynamical model to predict the interference effect of categorization on decision making. Knowl.-Based Syst. 2018, 150, 139-149. [CrossRef]

11. Liu, J.C.; Li, D.F. Corrections to "TOPSIS-based nonlinear-programming methodology for multi-attribute decision making with interval-valued intuitionistic fuzzy sets" [Apr 10 299-311]. IEEE Trans. Fuzzy Syst. 2018, 26, 391. [CrossRef]

12. Broumi, S.; Smarandache, F. Single valued neutrosophic trapezoid linguistic aggregation operators based multi-attribute decision making. Bull. Pure Appl. Sci. Math. Stat. 2017, 33e, 135. [CrossRef]

13. Deli, I.; Subas, Y. A ranking method of single valued neutrosophic numbers and its applications to multi-attribute decision making problems. Int. J. Mach. Learn. Cybern. 2017, 8, 1309-1322. [CrossRef]

14. Pramanik, S.; Dey, P.P.; Giri, B.C.; Smarandache, F. An Extended TOPSIS for Multi-Attribute Decision Making Problems with Neutrosophic Cubic Information; University of New Mexico: Albuquerque, NM, USA, 2017.

15. Figueira, J.; Greco, S.; Ehrogott, M. Multiple Criteria Decision Analysis: State of the Art Surveys. International 2018, 142, 192-202.

16. Siregar, D.; Arisandi, D.; Usman, A.; Irwan, D.; Rahim, R. Research of Simple Multi-Attribute Rating Technique for Decision Support. J. Phys. Conf. Ser. 2017, 930, 012015. [CrossRef]

17. Deng, X.; Jiang, W. Dependence assessment in human reliability analysis using an evidential network approach extended by belief rules and uncertainty measures. Ann. Nuclear Energy 2018, 117, 183-193. [CrossRef]

18. Deng, X. Analyzing the monotonicity of belief interval based uncertainty measures in belief function theory. Int. J. Intell. Syst. 2018, 33, 1869-1879. [CrossRef]

19. Li, Y.; Deng, Y. Generalized Ordered Propositions Fusion Based on Belief Entropy. Int. J. Comput. Commun. Control 2018, 13, 792-807. [CrossRef]

20. Deng, X.; Xiao, F.; Deng, Y. An improved distance-based total uncertainty measure in belief function theory. Appl. Intell. 2017, 46, 898-915. [CrossRef]

21. Zhang, X.; Mahadevan, S. Aircraft re-routing optimization and performance assessment under uncertainty. Decis. Support Syst. 2017, 96, 67-82. [CrossRef]

22. Huang, Z.; Yang, L.; Jiang, W. Uncertainty measurement with belief entropy on the interference effect in the quantum-like Bayesian Networks. Appl. Math. Comput. 2019, 347, 417-428. [CrossRef]

23. Jiang, W.; Hu, W. An improved soft likelihood function for Dempster-Shafer belief structures. Int. J. Intell. Syst. 2018, 33, 1264-1282. [CrossRef]

24. Zadeh, L.A. Fuzzy sets. Inf. Control 1965, 8, 338-353. [CrossRef] 
25. Atanassov, K.T. Intuitionistic fuzzy sets. Fuzzy Sets Syst. 1986, 20, 87-96. [CrossRef]

26. Han, Y.; Deng, Y. An enhanced fuzzy evidential DEMATEL method with its application to identify critical success factors. Soft Comput. 2018, 22, 5073-5090. [CrossRef]

27. Kang, B.; Deng, Y.; Hewage, K.; Sadiq, R. A method of measuring uncertainty for Z-number. IEEE Trans. Fuzzy Syst. 2018. [CrossRef]

28. Zhang, L.; Wu, X.; Qin, Y.; Skibniewski, M.J.; Liu, W. Towards a Fuzzy Bayesian Network Based Approach for Safety Risk Analysis of Tunnel-Induced Pipeline Damage. Risk Anal. 2016, 36, 278-301. [CrossRef] [PubMed]

29. Fei, L.; Wang, H.; Chen, L.; Deng, Y. A new vector valued similarity measure for intuitionistic fuzzy sets based on OWA operators. Iranian J. Fuzzy Syst. 2018. [CrossRef]

30. Yager, R.R. Some Aspects of Intuitionistic Fuzzy Sets; Kluwer Academic Publishers: Dordrecht, The Netherlands, 2009; pp. 67-90.

31. Li, D.F. TOPSIS-Based nonlinear-programming methodology for multiattribute decision making with interval-valued intuitionistic fuzzy sets. IEEE Trans. Fuzzy Syst. 2018, 26, 391. [CrossRef]

32. Bustince, H.; Burillo, P. Vague sets are intuitionistic fuzzy sets. Fuzzy Sets Syst. 1996, 79, 403-405. [CrossRef]

33. Szmidt, E.; Kacprzyk, J. Distances between intuitionistic fuzzy sets. Fuzzy Sets Syst. 2000, 114, 505-518. [CrossRef]

34. Torra, V. Hesitant fuzzy sets. Int. J. Intell. Syst. 2010, 25, 529-539. [CrossRef]

35. Xia, M.; Xu, Z. Hesitant fuzzy information aggregation in decision making. Int. J. Approx. Reason. 2011, 52, 395-407. [CrossRef]

36. Zhou, W.; Xu, Z.; Chen, M. Preference Relations Based on Hesitant-Intuitionistic Fuzzy Information and Their Application in Group Decision Making; Pergamon Press, Inc.: Oxford, UK, 2015; pp. 163-175.

37. Smarandache, F. A unifying field in logics: Neutrosophic logic. Multiple-Valued Logic 1999, 8, 489-503.

38. Smarandache, F. Neutrosophy: Neutrosophic Probability, Set, and Logic; American Research Press: Ann Arbor, Michigan, USA, 1998; 105p.

39. Atanassov, K.T. Interval Valued Intuitionistic Fuzzy Sets; Elsevier North-Holland, Inc.: Amsterdam, The Netherlands, 1989; pp. 343-349.

40. Wang, H.; Smarandache, F.; Zhang, Y.; Sunderraman, R. Single valued neutrosophic sets. In Proceedings of the 8th Joint Conference on Information Sciences, Salt Lake, UT, USA, 21-26 July 2005; pp. 94-97.

41. Ma, Y.X.; Wang, J.Q.; Wang, J.; Wu, X.H. An interval neutrosophic linguistic multi-criteria group decision-making method and its application in selecting medical treatment options. Neural Comput. Appl. 2017, 28, 2745-2765. [CrossRef]

42. Guo, Y.; Cheng, H.D. New Neutrosophic Approach to Image Segmentation; Elsevier Science Inc.: Amsterdam, The Netherlands, 2009; pp. 587-595.

43. Ye, J. A multicriteria decision-making method using aggregation operators for simplified neutrosophic sets. J. Intell. Fuzzy Syst. 2014, 26, 2459-2466.

44. Ye, J. Multicriteria decision-making method using the correlation coefficient under single-valued neutrosophic environment. Int. J. Gen. Syst. 2013, 42, 386-394. [CrossRef]

45. Ye, J. Single valued neutrosophic cross-entropy for multicriteria decision making problems. Appl. Math. Model. 2014, 38, 1170-1175. [CrossRef]

46. Xiao, F. A novel multi-criteria decision making method for assessing health-care waste treatment technologies based on D numbers. Eng. Appl. Artif. Intell. 2018, 71, 216-225. [CrossRef]

47. Deng, X.; Jiang, W. D number theory based game-theoretic framework in adversarial decision making under a fuzzy environment. Int. J. Approx. Reason. 2019, 106, 194-213. [CrossRef]

48. Jiang, W.; Zhong, Y.; Deng, X. A Neutrosophic Set Based Fault Diagnosis Method Based on Multi-Stage Fault Template Data. Symmetry 2018, 10, 346. [CrossRef]

49. Zhou, D.; Al-Durra, A.; Zhang, K.; Ravey, A.; Gao, F. Online remaining useful lifetime prediction of proton exchange membrane fuel cells using a novel robust methodology. J. Power Sources 2018, 399, 314-328. [CrossRef]

50. Şahin, R.; Yiğider, M. A multi-criteria neutrosophic group decision making metod based TOPSIS for supplier selection. arXiv 2014, arXiv:1412.5077.

51. Peng, J.J.; Wang, J.Q.; Zhang, H.Y.; Chen, X.H. An outranking approach for multi-criteria decision-making problems with simplified neutrosophic sets. Appl. Soft Comput. 2016, 27, 615-627. [CrossRef] 
52. Jiang, W.; Shou, Y. A novel single-valued neutrosophic set similarity measure and its application in multicriteria decision-making. Symmetry 2017, 9, 127. [CrossRef]

53. Tian, Z.; Zhang, H.; Wang, J.; Wang, J.; Chen, X. Multi-criteria decision-making method based on a cross-entropy with interval neutrosophic sets. Int. J. Syst. Sci. 2015, 47, 3598-3608. [CrossRef]

54. Deli, I.; Ali, M.; Smarandache, F. Bipolar neutrosophic sets and their application based on multi-criteria decision making problems. In Proceedings of the 2015 International Conference on Advanced Mechatronic Systems, Beijing, China, 22-24 August 2015; pp. 249-254.

55. Elhassouny, A.; Smarandache, F. Neutrosophic-simplified-TOPSIS multi-criteria decision-making using combined simplified-TOPSIS method and neutrosophics. In Proceedings of the 2016 IEEE International Conference on Fuzzy Systems (FUZZ-IEEE), Vancouver, BC, Canada, 24-29 July 2016; pp. 2468-2474.

56. Chai, Q.Z.; Li, P.; Di, R.; Zhang, Y.W. TOPSIS method based on single-valued neutrosophic set. J. Jiangsu Univ. Sci. Technol. (Nat. Sci. Ed.) 2018, 32, 262-265. (In Chinese)

57. Pramanik, S.; Pramanik, S.; Giri, B.C. TOPSIS method for multi-attribute group decision-making under single-valued neutrosophic environment. Neural Comput. Appl. 2016, 27, 727-737.

(C) 2019 by the authors. Licensee MDPI, Basel, Switzerland. This article is an open access article distributed under the terms and conditions of the Creative Commons Attribution (CC BY) license (http://creativecommons.org/licenses/by/4.0/). 